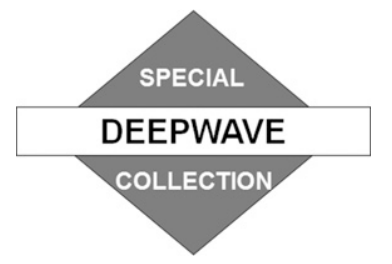

\title{
Unusual Trapped Mountain Lee Waves with Deep Vertical Penetration and Significant Stratospheric Amplitude
}

\author{
Johnathan J. Metz, Dale R. Durran, And Peter N. Blossey \\ Department of Atmospheric Sciences, University of Washington, Seattle, Washington
}

(Manuscript received 12 April 2019, in final form 4 November 2019)

\begin{abstract}
Simulations of the weather over the South Island of New Zealand on 28 July 2014 reveal unusual wave activity in the stratosphere. A series of short-wavelength perturbations resembling trapped lee waves were located downstream of the topography, but these waves were in the stratosphere, and their crests were oriented north-south, in contrast to both the northeast-southwest orientation of the spine of the Southern Alps and the crests of trapped waves present in the lower troposphere. Vertical cross sections through these waves show a nodal structure consistent with that of a higher-order trapped-wave mode. Eigenmode solutions to the vertical structure equation for two-dimensional, linear, Boussinesq waves were obtained for a horizontally homogeneous sounding representative of the 28 July case. These solutions include higher-order modes having large amplitude in the stratosphere that are supported by just the zonal wind component. Two of these higher-order modes correspond to trapped waves that develop in an idealized numerical simulation of the 28 July 2014 case. These higher-order modes are trapped by very strong westerly winds in the midstratosphere and are triggered by north-south-oriented features in the subrange-scale topography. In contrast, the stratospheric cross-mountain wind component is too weak to trap similar high-order modes with crest-parallel orientation.
\end{abstract}

\section{Introduction}

Gravity wave activity with maximum amplitude in the stratosphere downstream of major mountain ranges has previously been explained as a result of wave breaking inducing secondary wave generation (Bacmeister and Schoeberl 1989; Vadas et al. 2003), the trapping or partial trapping of gravity waves in a duct of high static stability in the tropopause inversion layer (Smith et al. 2016; Fritts et al. 2018) or the vertical propagation of waves through this layer from below. One potential further explanation is the presence of trapped mountain lee waves with very deep vertical penetration and significant amplitude in the stratosphere. Yet to the best of our knowledge, such waves have never been documented in observations, nor have they been simulated numerically or evaluated using linear theory for realistic atmospheric conditions.

In contrast, mountain lee waves with maximum amplitude in the lower troposphere are often observed downstream of topographic barriers. These waves have long been recognized as resonant modes supported by

Corresponding author: Johnathan J. Metz, jjmetz@uw.edu changes in the vertical profiles of static stability and cross-mountain wind (Scorer 1949; Corby and Wallington 1956). A few previous theoretical studies have also found trapped lee waves with significant amplitude in the stratosphere, but they were the result of calculations that imposed either a rigid lid at the upper boundary (Corby and Sawyer 1958) or an unbounded topmost atmospheric layer that did not support the vertical propagation of gravity waves because it was either unstratified (Corby and Sawyer 1958) or the Scorer parameter [defined in (12)] decayed exponentially with height (Danielsen and Bleck 1970). Under these assumptions, all the waves supported by their mathematical models were vertically trapped, creating an artificially full spectrum of trapped waves.

In this paper we will address the question, Is it possible for realistic atmospheric structures to produce trapped mountain lee waves with deep vertical penetration and significant amplitude in the stratosphere? The remainder of this paper is organized as follows. In section 2, stratospheric waves from a case-study simulation of relatively unusual conditions that occurred immediately after the end of the Deep Propagating Gravity Wave (DEEPWAVE) campaign are analyzed. This case 
study is then used as the impetus for idealized simulations in section 3. In section 4 we employ a linear eigenvalue solver to determine the wave modes predicted by linear theory for the atmospheric structure of the idealized simulation. The results of this linear analysis are then compared to the wave modes in the idealized simulation by examining their group velocities. Section 5 contains the conclusions.

\section{Simulated waves for 28 July 2014}

The DEEPWAVE campaign was conducted over New Zealand during the austral winter of 2014. While the core airborne field campaign was conducted from 6 June to 21 July, other instruments remained in place for a longer period (Fritts et al. 2016). Intriguing largeamplitude stratospheric vertical velocity perturbations were found in simulations of 28 July 2014, during which time a pronounced shortwave trough passed through the region, bringing strong cross-mountain flow. Gisinger et al. (2017) analyzed atmospheric conditions over New Zealand from June through August 2014. Their Fig. 3 demonstrates that while there were relatively strong $\left(>24 \mathrm{~m} \mathrm{~s}^{-1}\right.$ ) winds below $20 \mathrm{~km}$ during much of the DEEPWAVE campaign, only a couple of cases show a northwesterly to westerly wind transition with height (in particular at the end of June and July) and only one of these cases has monotonically increasing wind speed with height, precluding the existence of a valve layer (Kruse et al. 2016) and promoting wave trapping: 28 July.

Unfortunately, by this time, the aircraft had already departed, and the remaining ground-based instrumentation consisted of a wind profiler and radiosonde

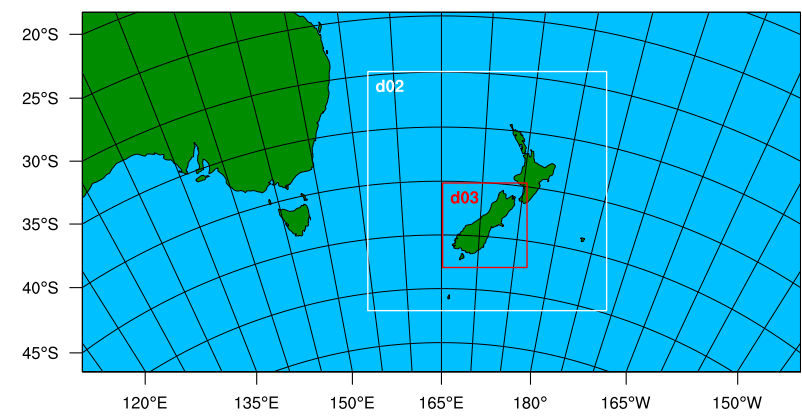

FIG. 1. Domain configuration for WRF simulation of $28 \mathrm{Jul}$ 2014. The boundary of the map represents the outermost domain. The inner domains are denoted as "d02" and "d03."

system at Hokitika and a Rayleigh lidar at Lauder. Hokitika is upstream of the spine of the Southern Alps and is therefore upstream of any trapped waves, and, as noted in Kaifler et al. (2015), the Rayleigh lidar is unreliable below $28-\mathrm{km}$ altitude due to potential contamination by stratospheric aerosols. Therefore, we regrettably proceed with analysis of this case without observations.

\section{a. Simulation configuration}

The simulation was conducted using version 3.8.1 of the Advanced Research version of WRF (WRF-ARW) Model (Skamarock et al. 2008). Three domains centered over a Lambert conformal conic projection of New Zealand were used with horizontal grid spacings of 18,6 , and $1 \mathrm{~km}$, as shown in Fig. 1 . Terrain was specified using the USGS GTOPO30 dataset after filtering to minimize forcing at poorly resolved short wavelengths. The filtering was done using a nine-point approximation to the two-dimensional Laplacian operator given by

$$
\tilde{h}_{i, j}=h_{i, j}+a\left[\sum\left(\left[\begin{array}{ccc}
\frac{1}{6} & \frac{2}{3} & \frac{1}{6} \\
\frac{2}{3} & -\frac{10}{3} & \frac{2}{3} \\
\frac{1}{6} & \frac{2}{3} & \frac{1}{6}
\end{array}\right] \circ\left[\begin{array}{ccc}
h_{i-1, j+1} & h_{i, j+1} & h_{i+1, j+1} \\
h_{i-1, j} & h_{i, j} & h_{i+1, j} \\
h_{i-1, j-1} & h_{i, j-1} & h_{i+1, j-1}
\end{array}\right]\right)\right],
$$

where $h_{i, j}$ is the terrain height at the grid point $(i, j) ; \tilde{h}$ is the smoothed terrain; ○ denotes the Hadamard, or Schur, product (element-by-element multiplication); and $\Sigma$ represents the sum of the nine elements in the product matrix. The coefficient $a$ is set to $3 / 16$ so that a checkerboard perturbation with wavelengths of $2 \Delta x$ and $2 \Delta y$ is eliminated in a single smoothing operation.

Initial and lateral boundary conditions were obtained from the National Centers for Environmental Prediction
(NCEP) Global Forecasting System (GFS) model analyses. The simulation was initialized at 0000 UTC 27 July 2014 and run for $48 \mathrm{~h}$ to 0000 UTC 29 July 2014 with lateral boundary conditions updated every $6 \mathrm{~h}$. The outermost domain was allowed to spin up for $6 \mathrm{~h}$ before the inner domains were initialized. Physical parameterizations used were Thompson microphysics, YSU planetary boundary layer (PBL) physics, Kain-Fritsch cumulus (for the outermost domain only), Dudhia shortwave and 
RRTM longwave radiation, Monin-Obukhov surface layer physics, and the Noah land surface model (LSM). The domain included 108 vertical levels, with vertical grid spacing increasing from $56 \mathrm{~m}$ near the surface to $1190 \mathrm{~m}$ at the top of the model. The model top was located at approximately $10 \mathrm{hPa}$, which corresponds to an approximate height of $30 \mathrm{~km}$. A Rayleigh-damping layer was imposed in the uppermost $8 \mathrm{~km}$ of the model domain to prevent spurious reflections off of the model top.

\section{b. Simulation results}

The simulated vertical velocity at 1300 UTC 28 July 2014 ( $31 \mathrm{~h}$ after initialization of the inner domains) is shown at three vertical levels in Fig. 2. Similar wave patterns were present for roughly $13 \mathrm{~h}$ between 0500 and 1800 UTC. As shown in Fig. 2a, at $3 \mathrm{~km}$ a "classic" trapped wave pattern is apparent, with the trapped waves oriented parallel to the main spine of the topography, that is, from southwest to northeast. Farther aloft, at $z=11 \mathrm{~km}$, the wave amplitude is greatly reduced with little evidence of the lower-level trapped waves remaining (Fig. 2b). Yet even farther aloft, at $z=15 \mathrm{~km}$, relatively strong widespread waves are again apparent, but in contrast to lower levels, many of the phase lines in these waves run north-south (Fig. 2c).

A vertical cross section from west to east through the wave field is shown in Fig. 3. As seen in Fig. 2c, there is relatively strong wave amplitude at high altitudes, specifically above approximately $z=13 \mathrm{~km}$. At $320<x<335 \mathrm{~km}$ and above $z=13 \mathrm{~km}$ (above the upper thin black line), there is upstream tilt with height, perhaps indicating some vertical propagation in this region. However, throughout the rest of this cross section, at $335<x<380 \mathrm{~km}$ and above $z=13 \mathrm{~km}$, the phase lines are roughly vertical, which is consistent with wave trapping. The vertical velocities are nearly zero at the 13-km level, and change sign across that level, suggesting the presence of a nodal line. A second, less clearly defined, nodal line may be present near $z=10.5 \mathrm{~km}$ (lower thin black line). The vertical velocities below $10.5 \mathrm{~km}$ are more chaotic, including perhaps a vertically propagating wave above the low ridge at $x=342 \mathrm{~km}$.

\section{Idealized 3D simulations}

To better isolate the dynamics responsible for the complex pattern of waves in Figs. 2 and 3, we shift to a more in-depth analysis of a simulation with idealized terrain, horizontally uniform large-scale atmospheric forcing, and simplified dynamics.

\section{a. Simplified WRF configuration}

In contrast to the previous case-study, the idealized simulation was run without moisture, Coriolis forces, and
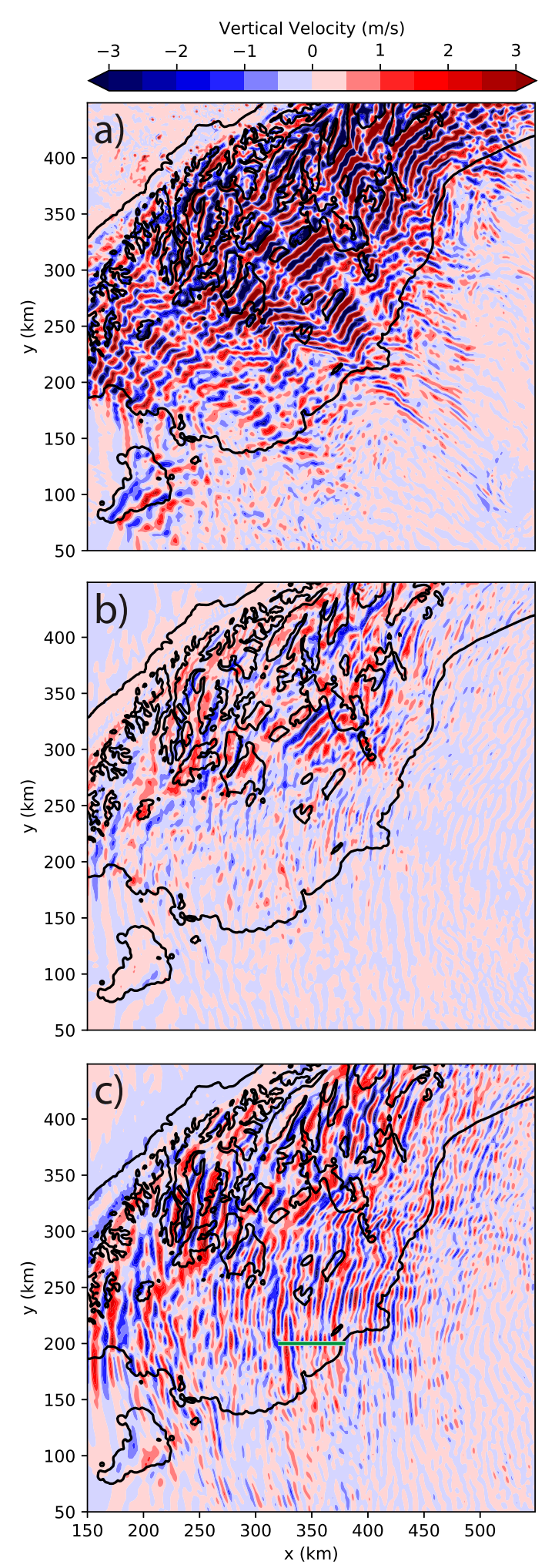

FIG. 2. Simulated vertical velocity (color fill; $\mathrm{m} \mathrm{s}^{-1}$ ) at hour 31 (1300 UTC 28 Jul 2014) on a subdomain of the finest grid at heights of (a) 3, (b) 11, and (c) $15 \mathrm{~km}$. Black lines show the coast and the 1000-m terrain contour. Green line segment in (c) shows the location of the vertical cross section in Fig. 3. 


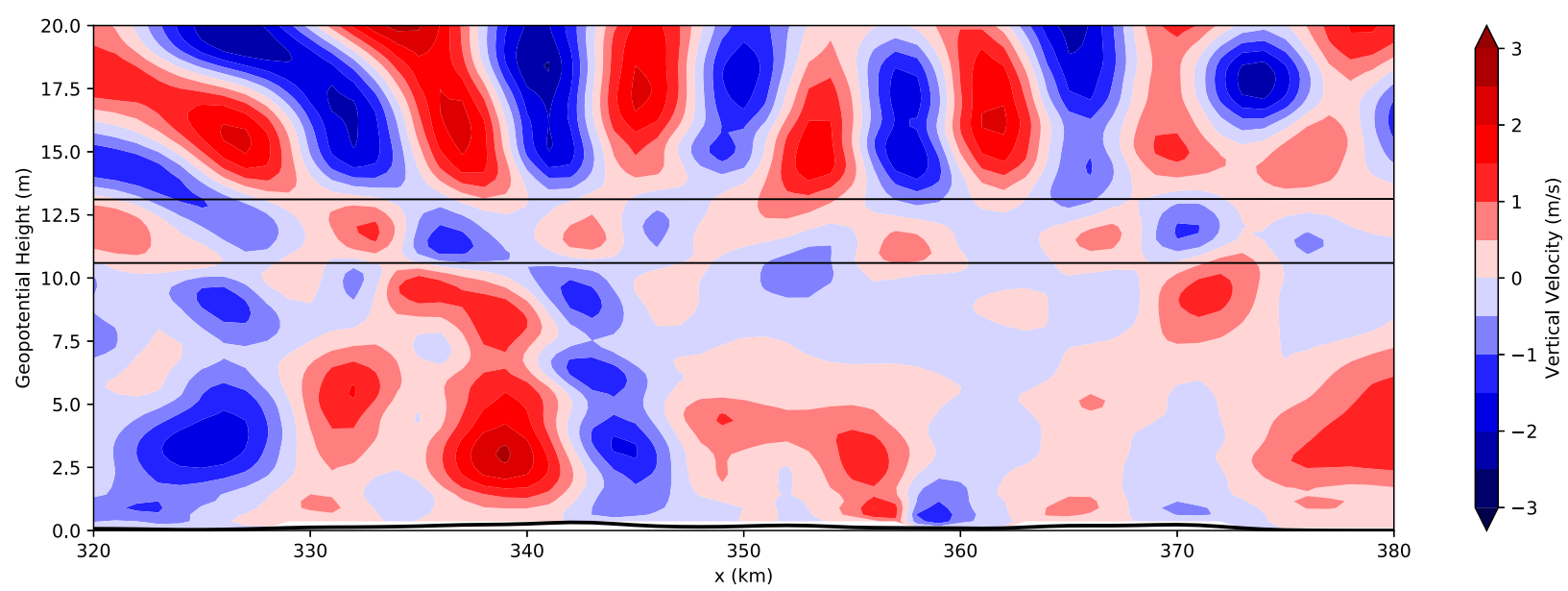

FIG. 3. Vertical cross section of the simulated $w$ field $\left(\mathrm{m} \mathrm{s}^{-1}\right)$ at $320<x<380 \mathrm{~km}$ and $y=200 \mathrm{~km}$ (indicated by the green line in Fig. 2c) at 1300 UTC 28 Jul 2014. The terrain height is shown by the black line at the bottom. Apparent nodal lines have been indicated by the thin horizontal black lines.

without any physical parameterizations except for turbulent mixing. The lower boundary condition was free slip and the initial conditions consisted of potential flow over the terrain. This simulation used a horizontal resolution of $1 \mathrm{~km}$, which is the same as the resolution of the inner mesh of the case-study simulation. The domain extended for $798 \mathrm{~km}$ in the horizontal, while the vertical grid consisted of 135 vertical layers extending to the same $30-\mathrm{km}$ depth as the case-study simulation, corresponding to a resolution of $172 \mathrm{~m}$ at the surface stretching to a resolution of $908 \mathrm{~m}$ at the model top. A Rayleigh damping layer was imposed in the uppermost $10 \mathrm{~km}$ of the domain. The large and small time steps were 5 and $5 / 6 \mathrm{~s}$, respectively.

To verify that the Rayleigh damping layer has negligible impact on the formation of the stratospheric trapped waves, a second idealized simulation was performed with the University of Washington meso12 model, using a local-in-space radiation condition at the upper boundary at $z=30 \mathrm{~km}$ instead of a Rayleigh damping layer. The formulation of the radiation condition is described in Durran (2010, p. 484); perfect upward transmission was specified for wavelengths of 9,36 , and $72 \mathrm{~km}$. In addition to providing a second simulation with a completely different formulation of the wave-permeable upper-boundary condition, the numerics in the meso12 simulation are very different from those in WRF, thereby providing a check on the model-independence of our solution. The meso12 model was employed in a formulation very similar to that presented in Durran and Klemp (1983). Aside from the upper-boundary condition, the only difference in the domain configuration between the meso12 simulation and the idealized WRF simulation is the vertical grid. The meso12 simulation used 120 levels with $\Delta z=250 \mathrm{~m}$, whereas WRF used 135 levels on a stretched mesh.
Key simulation parameters for all three numerical simulations (case study and idealized) are provided in Table 1.

\section{b. Idealized terrain}

The idealized terrain consisted of one main ridge, oriented from southwest to northeast in the same manner as the main spine of the Southern Alps. In addition, smaller side ridges (subscript "sr") extended southward from the main ridge (subscript "mr") to represent smallscale secondary ridges and valleys typical of the Southern Alps (Fig. 4a). The terrain profile is given by

$$
h(x, y)=h_{\mathrm{mr}}(x, y)+\sum_{n=0}^{6}\left[h_{\mathrm{sr}}(x, y, n) \frac{h_{\mathrm{mr}}(x, y+60 \mathrm{~km})}{h_{m}}\right],
$$

where

$$
\begin{aligned}
h_{\mathrm{mr}}(x, y)= & \left\{\begin{array}{cc}
\frac{h_{m}}{16}\left[1+\cos \left(\pi r_{\mathrm{mr}}\right)\right]^{4}, & r_{\mathrm{mr}}<1 \\
0, & r_{\mathrm{mr}} \geq 1
\end{array}\right. \\
r_{\mathrm{mr}}= & {\left[\alpha\left(x, L_{x}\right)\left(\frac{x^{\prime}-L_{x} \operatorname{sgn}\left(x^{\prime}\right)}{4 a}\right)^{2}\right.} \\
& \left.+\alpha\left(y, L_{y}\right)\left(\frac{y^{\prime}-L_{y} \operatorname{sgn}\left(y^{\prime}\right)}{4 a}\right)^{2}\right]^{1 / 2}, \\
\alpha(c, d)= & \begin{cases}0, & |c|<d \\
1, & |c| \geq d\end{cases} \\
x^{\prime}= & \left(x-x_{0}\right) \cos \theta+\left(y-y_{0}\right) \sin \theta
\end{aligned}
$$


TABLE 1. Summary of the configurations of the three simulations used in this study.

\begin{tabular}{llll}
\hline & \multicolumn{1}{c}{ Case study WRF } & \multicolumn{1}{c}{ Simplified WRF } & \multicolumn{1}{c}{ meso12 } \\
\hline Vertical grid spacing & $56 \mathrm{~m}$, stretching to $1190 \mathrm{~m}$ & $172 \mathrm{~m}$, stretching to $908 \mathrm{~m}$ & $250 \mathrm{~m}$ \\
Wind profile & Fully evolving & Fixed horizontally homogeneous & Fixed horizontally homogeneous \\
Terrain profile & Real NZ & Idealized & Idealized \\
Lower boundary & Full surface layer & Free slip & Free slip \\
Upper boundary & Damping layer & Damping layer & Radiation condition \\
& $22 \leq z \leq 30 \mathrm{~km}$ & $20 \leq z \leq 30 \mathrm{~km}$ & $z=30 \mathrm{~km}$ \\
Physical parameterizations & Full (see text) & Turbulent mixing only & Turbulent mixing only \\
\hline
\end{tabular}

$$
\begin{aligned}
y^{\prime} & =\left(y-y_{0}\right) \cos \theta-\left(x-x_{0}\right) \sin \theta, \\
h_{\mathrm{sr}}(x, y, n) & =\left\{\begin{array}{cc}
\frac{h_{m}}{16}\left[1+\cos \left(\pi r_{\mathrm{sr}}\right)\right]^{4}, & r_{\mathrm{sr}}<1 \\
0, & r_{\mathrm{sr}} \geq 1
\end{array}\right. \\
r_{\mathrm{sr}} & =\left|\frac{x-\left(r_{0}+\lambda_{r} n\right)}{4 b}\right|,
\end{aligned}
$$

$\theta=-55^{\circ}$ is the orientation of the normal of the main ridge relative to east, and $h_{m}=300 \mathrm{~m}$ is the maximum mountain height. The main ridge was centered at $\left(x_{0}\right.$, $\left.y_{0}\right)=(350 \mathrm{~km}, 450 \mathrm{~km})$ and incorporated a flat "plateau" at the top, which was $L_{x}=15 \mathrm{~km}$ wide and $L_{y}=300 \mathrm{~km}$ long. The maximum height of the side ridges was also $h_{m}=$ $300 \mathrm{~m}$. The half width of the main ridge was $a=10 \mathrm{~km}$, while the half width of the side ridges was $b=5.5 \mathrm{~km}$. The side ridges were $\lambda_{r}=66 \mathrm{~km}$ apart, with the first side ridge located at $r_{0}=152 \mathrm{~km}$. The resulting terrain profile is shown in Fig. $4 \mathrm{~b}$.

The 66-km distance between the side ridges is a multiple of the approximately $11-\mathrm{km}$ wavelength of the north-south-oriented waves apparent in Fig. 2c. The 300-m-high topography is substantially lower than the actual Southern Alps because we want to clearly reveal the linear mountain wave response, and also because these are free-slip simulations that tend to produce stronger waves than simulations that include surface stress.

\section{c. Idealized input sounding}

The construction of a horizontally homogeneous background environment representative of the conditions upstream of the South Island at 1300 UTC 28 July 2014 proceeded in several steps. First, the full 1300 UTC horizontal wind field on the innermost nest from the real-case simulation was low-pass filtered with a wavelength cutoff of $200 \mathrm{~km}$. Then this filtered velocity field was sampled in a vertical cross section just upstream of the Southern Alps, above a line passing through the point $(x, y)=(300 \mathrm{~km}, 350 \mathrm{~km})$ at a compass heading of $55^{\circ}$, as shown by the red line in Fig. 5. The winds in this cross section were then replicated throughout the domain along lines perpendicular to the cross section. As shown in Fig. 5, this replicated field contains regions of
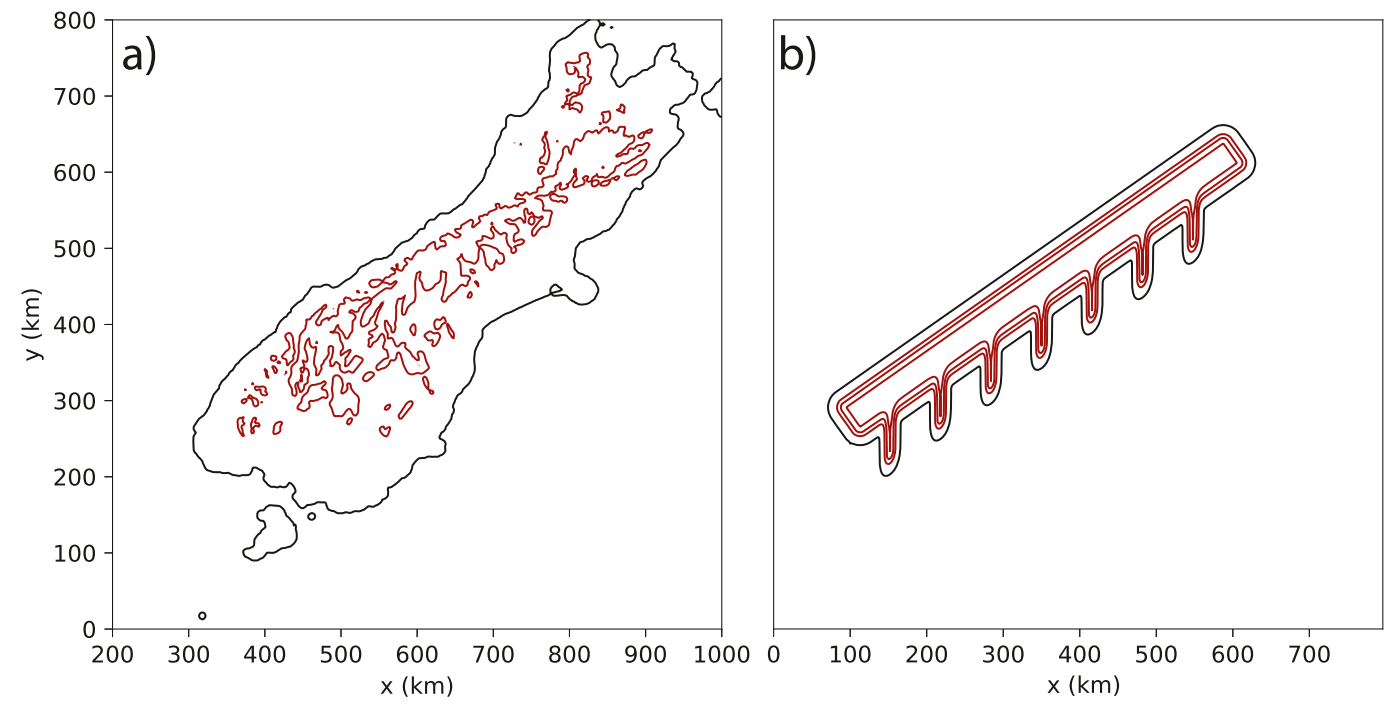

FIG. 4. (a) Topography of the South Island of New Zealand. Contours of 1 (black) and $1000 \mathrm{~m}$ (brown) are shown. (b) Domain and terrain profile used for the idealized simulation. Contours of 1- (black) and 100-, 200-, and 300-m (brown) elevation are shown. 


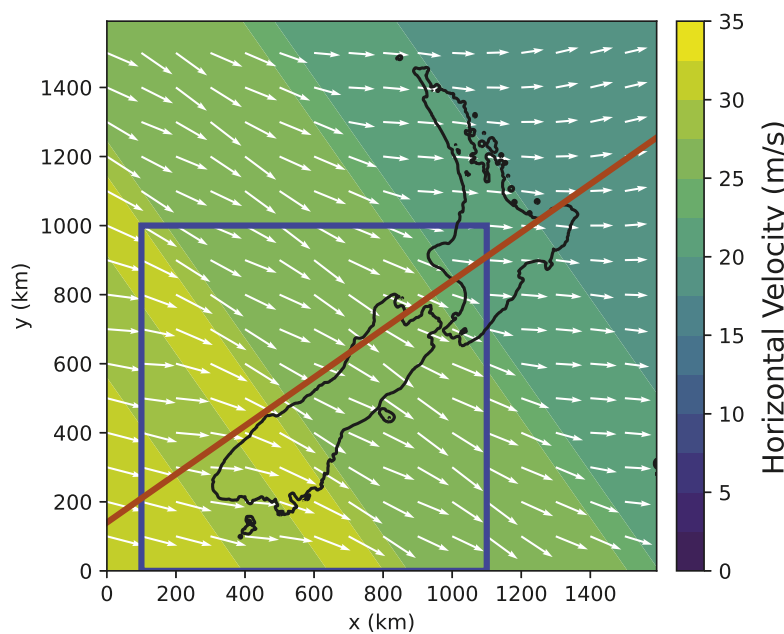

FIG. 5. Initial conditions for horizontal velocity at $15 \mathrm{~km}$ for the simulation used to generate the horizontally uniform sounding for the idealized simulation. Horizontal velocity vectors and wind speed (color fill; $\mathrm{m} \mathrm{s}^{-1}$ ). The red line denotes the location of the cross section used to generate these initial conditions from the full 3D flow. The blue box is the averaging domain for the adjusted shear flow. The outline of New Zealand is for reference only; the actual simulation did not incorporate terrain.

horizontal convergence and divergence. A vertical thermodynamic profile representative of the domain-averaged conditions was specified by the piecewise constant BruntVäisälä frequency profile:

$$
N(z)= \begin{cases}0.01 \mathrm{~s}^{-1}, & 0 \leq z<2 \mathrm{~km} \\ 0.015 \mathrm{~s}^{-1}, & 2 \leq z<4 \mathrm{~km} \\ 0.005 \mathrm{~s}^{-1}, & 4 \leq z<8 \mathrm{~km} \\ 0.02 \mathrm{~s}^{-1}, & z \geq 8 \mathrm{~km} .\end{cases}
$$

The boundary conditions were then fixed, and the flow was integrated for $8.5 \mathrm{~h}$ to approximately steady state without terrain present to achieve an almost balanced wind field. The now essentially uniform balanced flow was then averaged horizontally upstream of the location corresponding to the South Island over the box $(100<x<1100 \mathrm{~km}, 0<y<1000 \mathrm{~km})$. The location of the averaging box is also shown in Fig. 5. The resulting sounding is shown in Fig. 6.

\section{d. Idealized $3 D$ simulation results}

The vertical velocity field after $10 \mathrm{~h}$ of integration of the idealized simulation is plotted at three different elevations in Fig. 7. By this time, the waves have approximately reached steady state, and, in comparison to the real-data run, the waves have a much more regular structure. As in the 28 July case (Fig. 2), there is a relative minimum in wave amplitude at $z=11 \mathrm{~km}$ (Fig. 7b), while higher up, at a height of $15 \mathrm{~km}$ (Fig. 7c), largeamplitude perturbations are again evident with phase lines running approximately north-south. For comparison, the vertical velocity field from the meso12 simulation is shown in Fig. 8. The wave patterns generated by these two rather different numerical models are very similar.

Nearer the surface, at $z=3 \mathrm{~km}$ (Fig. 7a), two lines of strong updrafts appear parallel to and immediately downstream of the main crest, but in contrast to the 28 July case, these trapped waves do not dominate the $w$ field farther downstream of the mountain. Instead, the ridge-parallel trapped waves appear to be superimposed on a pattern of shorter-wavelength waves whose crests run roughly north-south. Even farther downstream, the ridge-parallel features disappear leaving only the north-south waves and a series of northwest to southeast-oriented nodal lines that are possibly associated with the ends of the subrange-scale ridges. The ridge-parallel waves are likely more dominant in
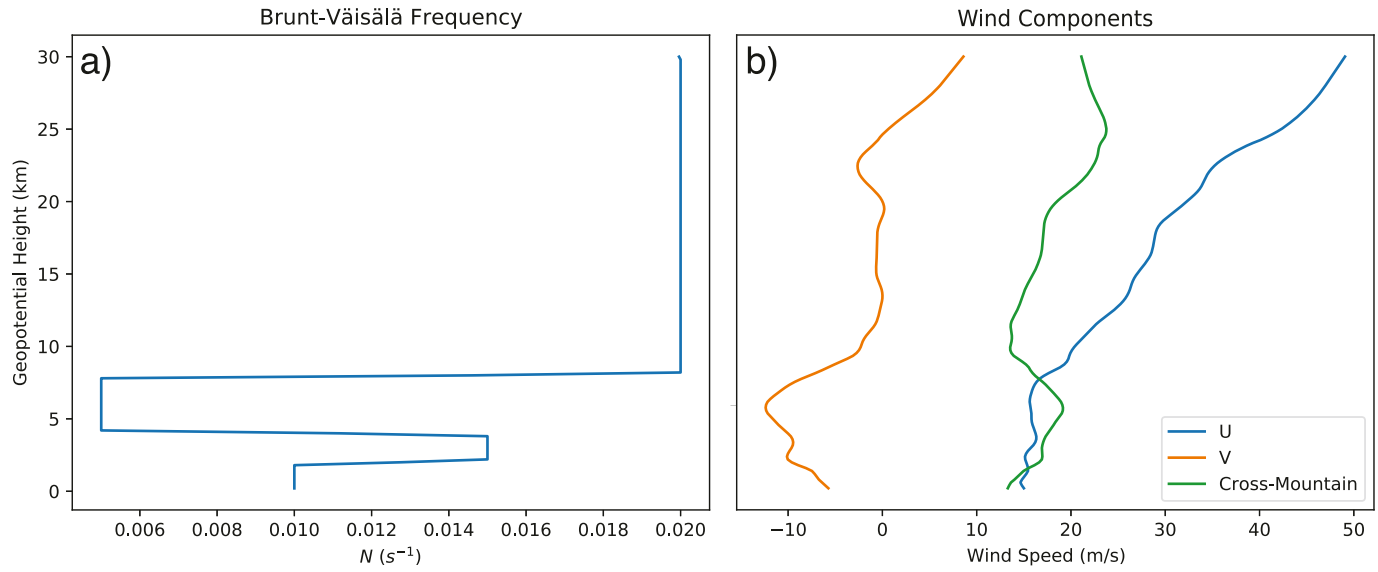

FIG. 6. Vertical profiles of the horizontally uniform environmental conditions for the idealized simulation

(a) Brunt-Väisälä frequency $\left(\mathrm{s}^{-1}\right)$ and (b) zonal $(U)$, meridional $(V)$, and cross-mountain wind components $\left(\mathrm{m} \mathrm{s}^{-1}\right)$. 

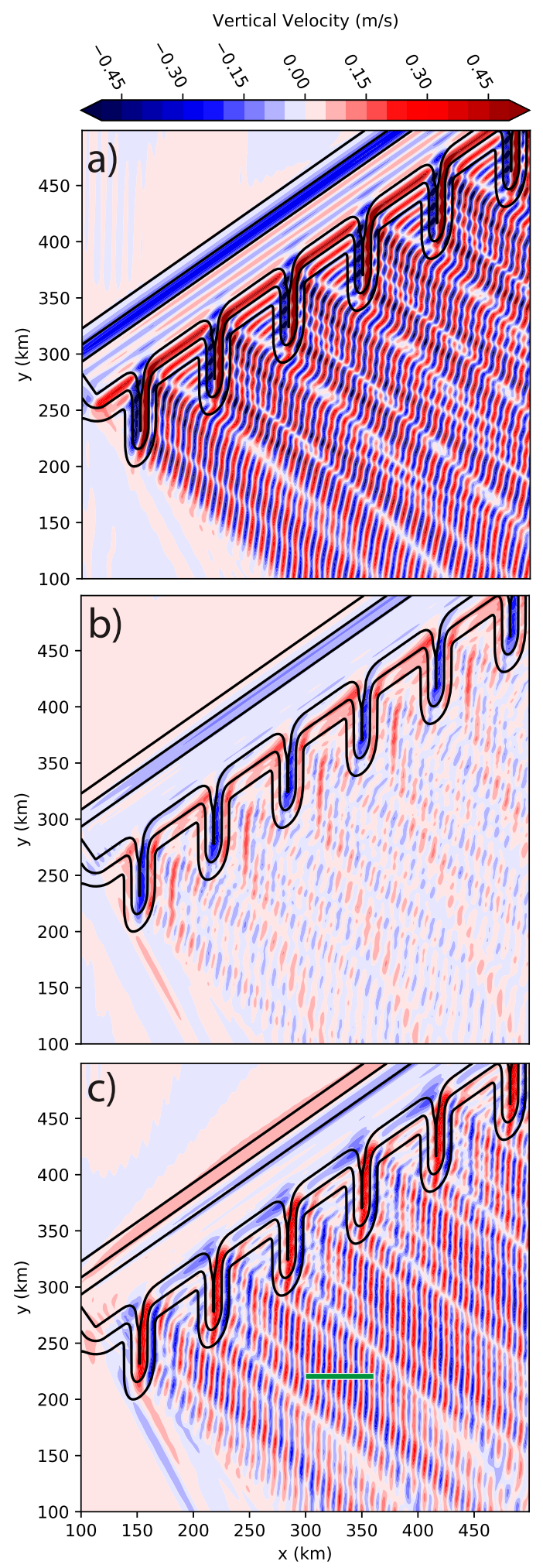

FIG. 7. Vertical velocities (color fill; $\mathrm{m} \mathrm{s}^{-1}$ ) at hour 10 over a subdomain of the idealized WRF simulation at heights of (a) 3, (b) 11, and (c) $15 \mathrm{~km}$. Thin black lines show the coast and the 100 - and $300-\mathrm{m}$ terrain contours. Green line segment in (c) indicates the location of the cross section in Fig. 9. the 28 July case study, because in that simulation the main ridge of the Southern Alps extends to typical heights of $2 \mathrm{~km}$, and the more nonlinear flow response in the lee of that ridge forces the short-wavelength trapped waves more efficiently than the wide 300 -m-high ridge in the idealized simulation (Durran 2015).

An $x-z$ vertical cross section through these waves above the line $300<x<360 \mathrm{~km}, y=220 \mathrm{~km}$ is shown in Fig. 9a. In the central portion of the cross section, the phase lines are essentially vertical. There are also two nodal lines at approximately $z=7.5 \mathrm{~km}$ and $z=11 \mathrm{~km}$, suggesting that some type of higher-order trapped mode is present. For comparison, a vertical cross section in the same location from the meso12 simulation is shown in Fig. 9b. There are only minor differences between the two simulations, once again suggesting that the Rayleigh damping layer does not have major impact on the trapped-wave modes.

\section{Linear trapped-wave modes}

How do the waves in the preceding idealized simulation compare with the trapped-wave modes predicted by linear theory? Neglecting Coriolis forces, the linearized, steady-state, inviscid, Boussinesq, two-dimensional wave equation for the vertical velocity perturbation $w$ is

$$
\left(\frac{\partial^{2}}{\partial x^{2}}+\frac{\partial^{2}}{\partial z^{2}}\right) w+\left(\frac{N^{2}}{U^{2}}-\frac{1}{U} \frac{d^{2} U}{d z^{2}}\right) w=0
$$

where $N(z)$ is the Brunt-Väisälä frequency and $U(z)$ is the basic-state wind speed (Gill 1982). Defining the Scorer parameter $l$ such that

$$
l^{2}=\frac{N^{2}}{U^{2}}-\frac{1}{U} \frac{d^{2} U}{d z^{2}}
$$

and Fourier transforming (11) with respect to $x$, we obtain the vertical structure equation for the vertical velocity at horizontal wavenumber $k, \hat{w}(k, z)$ :

$$
\frac{d^{2} \hat{w}}{d z^{2}}+\left(l^{2}-k^{2}\right) \hat{w}=0
$$

Using environmental profiles of $U(z)$ and $N(z)$ from the idealized simulation we evaluate the eigenvalues and eigenfunctions of (13) numerically. The solver used in this study is a refined and generalized version of that described in Durran et al. (2015). While Durran et al. (2015) obtained eigenvalues and eigenfunctions of (13) for atmospheric profiles with piecewise constant BruntVäisälä frequency and piecewise linear wind profiles, the present work is concerned with continuously varying atmospheric profiles. Using the same approach as 

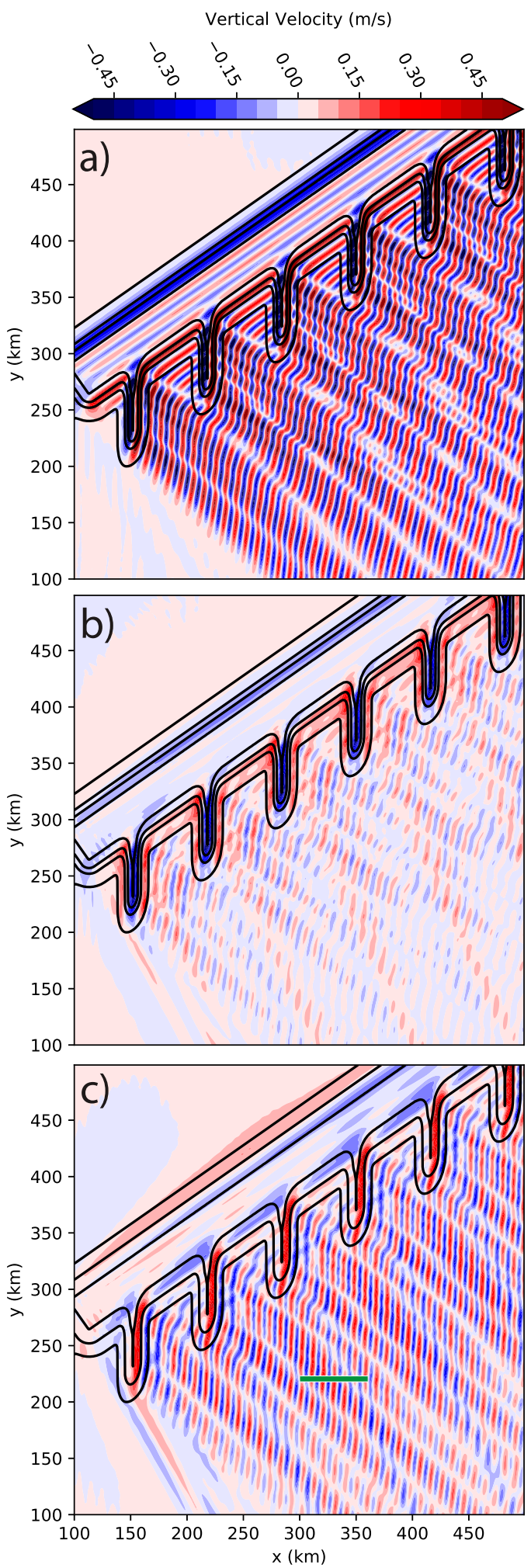

FIG. 8. As in Fig. 7, but for the idealized meso12 simulation. described in the appendix of Durran et al. (2015), (13) is discretized in layers $H_{i}<z<H_{i+1}$ with the Chebyshev collocation method applied in each layer. Matching conditions are applied between the layers. In addition to continuity of $\hat{w}(k, z)$, its first derivative $d \hat{w} / d z$ is continuous across the interface between layers of the discretization, and these conditions are enforced on all solutions. ${ }^{1}$ With the finer-scale variations characteristic of a continuous sounding, the solutions are discretized using more layers (60 layers of thickness $500 \mathrm{~m}$ ) and fewer Chebyshev collocation points within each layer (10 in our computations) than in Durran et al. (2015). Because the wave radiation upper-boundary condition depends on the wavenumber $k$, the eigenvalue problem is nonlinear and is solved by the iterative method described in Durran et al. (2015).

\section{a. Eigenfunctions and eigenvalues}

Based on the orientation of the waves in both the 28 July case and the idealized simulations, we apply the solver separately to the winds in vertical planes perpendicular to the main ridge (winds emanating from $325^{\circ}$ ) and perpendicular to the subrange-scale ridges (winds emanating from $270^{\circ}$ ). With Coriolis forces neglected, the horizontally uniform basic-state wind component parallel to the wave crest has no influence on the linear solution, and the total wave response downstream of the topography can be a superposition of the resonant waves supported by the atmospheric profiles from each cross section.

Evaluating the Scorer parameter [see (12)] using the thermodynamic and westerly wind profiles shown in Fig. 6 yields the profile shown in Fig. 10a, for which the numerical solver finds the three trapped-wave modes whose vertical structure is illustrated by the plots of $\operatorname{Re}(\hat{w})$ (blue) in Figs. 10b-d. As an aid to visualizing the wave amplitude, a line segment of length $[-|\hat{w}|,|\hat{w}|]$ is indicated by gray shading at each elevation. The eigenmode solver is Boussinesq, so for quantitative comparison between the simulated $w$ and the vertical profiles in Fig. 12, $\hat{w}(z)$ should be multiplied by $[\rho(0) / \rho(z)]^{1 / 2}$, where $\rho$ is the density. The density-adjusted vertical profiles are shown by the green curves in Figs. 10b-d.

These waves could be potentially present in the idealized numerical simulation if they are triggered by flow over the subrange-scale ridges. All three modes have significant amplitude in the stratosphere. The wave energy lost through leakage into the upper atmosphere $D_{\lambda}$,

\footnotetext{
${ }^{1}$ In Durran et al. (2015), discontinuities in $d U / d z$ between layers would induce compensating discontinuities in $d \hat{w} / d z$ following their (A2).
} 

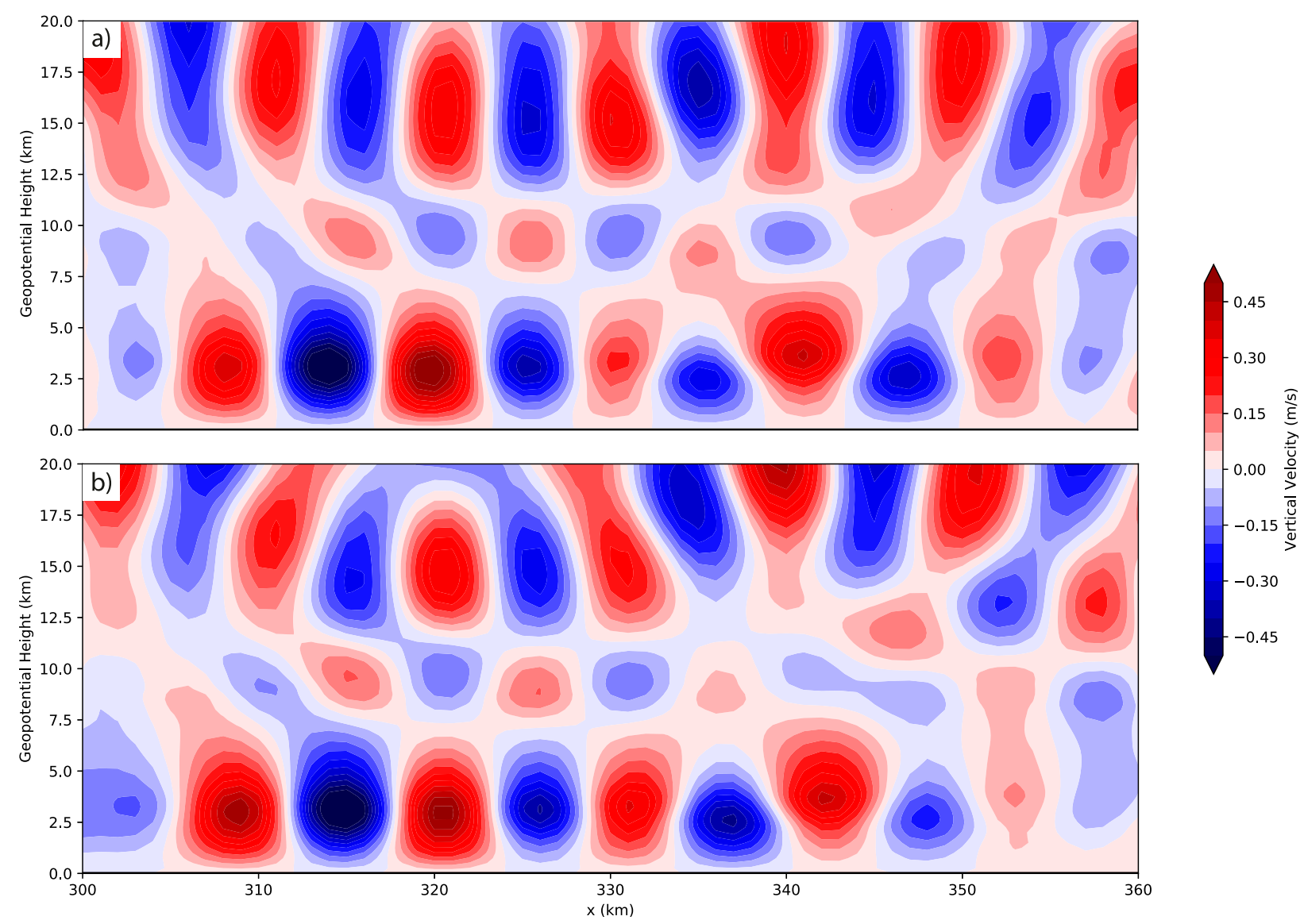

FIG. 9. Vertical cross section of the $w$ field $\left(\mathrm{m} \mathrm{s}^{-1}\right)$ above the segment $300<x<360 \mathrm{~km}$ and $y=220 \mathrm{~km}$ (indicated by the green line in Fig. 7c) at hour 10 of the (a) idealized WRF simulation and (b) idealized meso12 simulation.

expressed as the percentage loss in amplitude per unit wavelength, is zero for all of the modes, indicating that they are all completely trapped. Also plotted in Fig. 10a are the values of the horizontal wavenumber squared $k^{2}$ for each resonant mode. From (13), regions of wave trapping can occur if $k^{2}>l^{2}$ throughout a deep layer of the atmosphere aloft, because if $l^{2}$ were constant, $\hat{w}$ must decay exponentially with height to preserve the boundedness of the solution. Although not strictly constant, $l^{2}$ is slowly varying with height and less than $k^{2}$ near the top of the domain for all three modes. Thus, it is unsurprising that the eigenfunction solver found these modes to be completely trapped.

The lowest-order resonant mode, with one nodal line, has a wavelength of $9.28 \mathrm{~km}$, which is almost identical to the $9.50-\mathrm{km}$ wavelength for the nextorder mode with two nodal lines. The highest-order mode has a wavelength of $11.61 \mathrm{~km}$. All modes have a nodal line in the layer $10<z<11.5 \mathrm{~km}$, which could account for the weak vertical velocity signatures at the 11-km level in Fig. 7. In addition, the second mode has another nodal line at approximately $7 \mathrm{~km}$, and the third has additional nodal lines at approximately 5 and $15.5 \mathrm{~km}$.

The Scorer parameter, evaluated using the $325^{\circ}$ wind component perpendicular to the main ridge, is shown in Fig. 11a. As in the previous case (Fig. 10a), the Scorer parameter in the upper troposphere is substantially smaller than that in the lower troposphere, which would favor at least partial trapping. But as apparent in Fig. 6, the northerly wind component drops almost to zero at heights above $10 \mathrm{~km}$, and as a consequence, the increase in speed of the $325^{\circ}$ wind component with height throughout the stratosphere is much weaker than the corresponding increase in the speed of the westerly wind component. Because the stratospheric winds are weaker, the Scorer parameter is larger in this case at all heights above $8 \mathrm{~km}$. As a consequence, $l^{2}$ exceeds the square of the horizontal wavenumber (Fig. 11a) throughout the stratosphere, permitting the vertical propagation of this mode. Thus, in contrast to the fully trapped modes supported by the westerly wind component, all the eigenfunctions supported by the $325^{\circ}$ flow leak energy to upper levels. The mode shown in Fig. 11b is, nevertheless, 

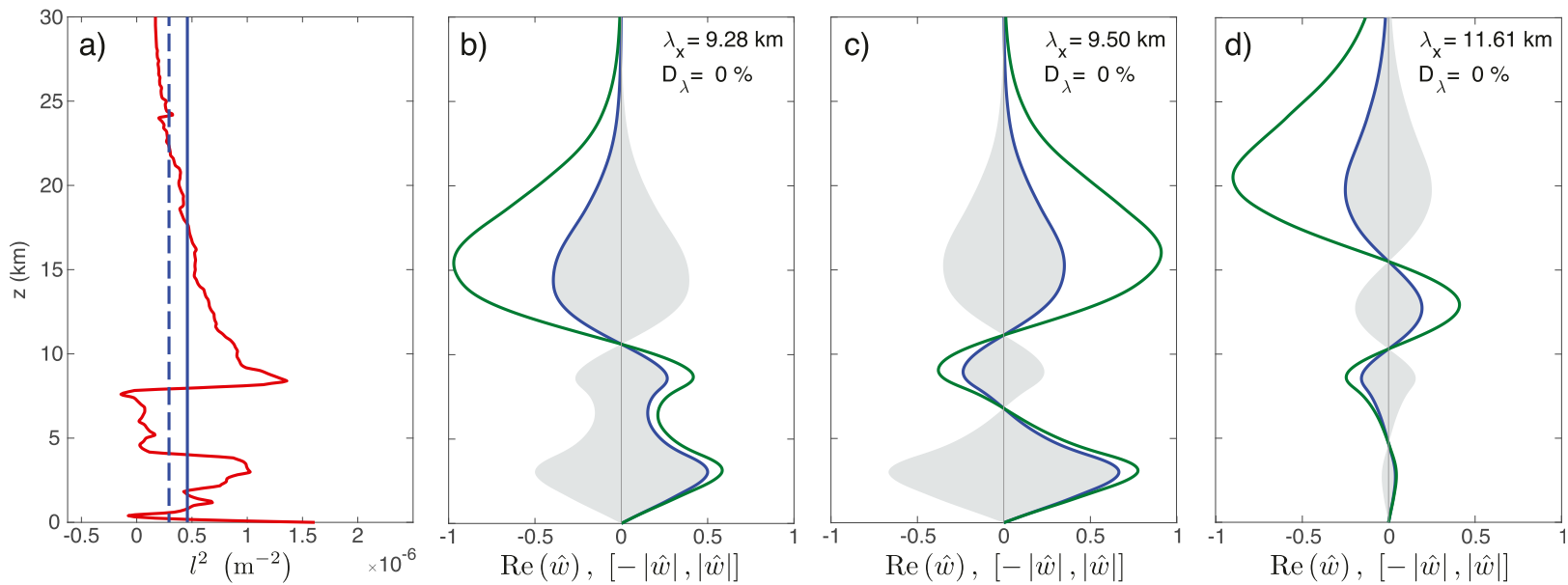

FIG. 10. Vertical profiles from the idealized sounding of (a) Scorer parameter squared $l^{2}\left(\mathrm{~m}^{-2}\right.$; red) and horizontal wavenumber squared $k^{2}\left(\mathrm{~m}^{-2}\right.$; blue) for modes 1 and 2 (solid) and mode 3 (dashed) and (b)-(d) Boussinesq (blue) and density-adjusted (green) trapped-wave amplitude $\operatorname{Re}(\hat{w})$ evaluated using the westerly component of the total wind field. Gray shading shows width of segment $[-|\hat{w}|,|\hat{w}|]$ as an aid to visualization. The horizontal wavelength $\lambda_{x}$ and percentage decay per wavelength $D_{\lambda}$ are noted for each mode.

almost trapped because its downstream decay rate is just $2.5 \%$ per wavelength. The structure of this mode is more typical of commonly observed lee waves, having its maximum amplitude in the lower troposphere. Note that the $10.45-\mathrm{km}$ wavelength of this mode also falls within the range of resonant wavelengths supported by the westerly flow.

\section{b. Computation of group velocities}

How do the waves computed as solutions to the preceding linear eigenvalue problem compare with the disturbances present in the full idealized simulation? Trapped waves parallel to the main ridge dominate the $w$ field very close to the mountain in Fig. 7a. These waves have a wavelength of $10.6 \mathrm{~km}$, decay with height, and also gradually decay downstream where their contribution to the total vertical velocity field gradually becomes dominated by waves with north-south phase lines. These waves have the modal structure shown in Fig. 11b.

Distinguishing the contributions from the three different modes in Fig. 10 is more challenging, since their phase lines all have the same north-south orientation and their wavelengths are very similar. It is, therefore, helpful to exploit the differences in their group velocities to search for wave packets propagating along the ray paths predicted for each mode.

Letting $\omega$ be the frequency, $k$ the zonal wavenumber, and $c$ the phase speed, the east-west group velocity $c_{g_{x}}$ satisfies

$$
c_{g_{x}}=\frac{\partial \omega}{\partial k}=\frac{\partial c}{\partial k} k+c \approx \frac{\Delta c}{\Delta k} k+c
$$

Here we have used the definition $\omega=c k$ and approximated the derivative with finite differences. Our eigenvalue solver can obtain solutions for waves with nonzero phase speeds, so we compute the group velocity for each mode using a centered difference, solving for pairs of resonant wavelengths with phase speeds of 0.5 and $-0.5 \mathrm{~m} \mathrm{~s}^{-1}$ and determining $\Delta k$ from their difference. The computed group velocities, along with the other salient properties of the trapped modes, are listed in Table 2 .

\section{c. Comparison of ray paths}

To isolate the waves associated with a single trappedwave mode, it is helpful to examine the $w$ field at elevations where the other two modes have minimal amplitude.
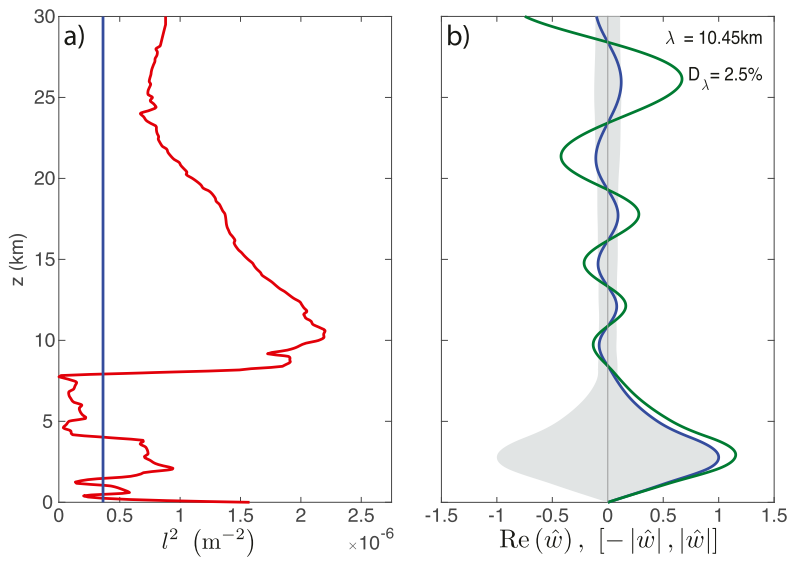

FIG. 11. As in Fig. 10, but evaluated using the cross-mountain component of the total wind field. There is only one significant eigenmode. 
TABLE 2. Properties of the three zonal modes and the crossmountain mode determined by the eigenvalue solver: wavelength $\lambda(\mathrm{km})$, downstream decay per wavelength $D_{\lambda}(\%)$, group velocity $c_{g_{v}}\left(\mathrm{~m} \mathrm{~s}^{-1}\right)$, and direction of propagation $\theta$ (degrees from due east). The computed $c_{g_{x}}$ for CM mode $\left(10.2 \mathrm{~m} \mathrm{~s}^{-1}\right)$ is based upon a total group velocity of $17.8 \mathrm{~m} \mathrm{~s}^{-1}$ and a propagation direction of $-55^{\circ}$.

\begin{tabular}{lcccc}
\hline \hline & Mode 1 & Mode 2 & Mode 3 & CM mode \\
\hline$\lambda$ & 9.28 & 9.50 & 11.61 & 10.45 \\
$D_{\lambda}$ & 0 & 0 & 0 & 2.5 \\
$c_{g_{x}}$ & 14.4 & 12.6 & 16.6 & 10.2 \\
$\theta$ & $-36^{\circ}$ & $-40^{\circ}$ & $-32^{\circ}$ & - \\
\hline
\end{tabular}

Mode 3 decays much more slowly with height in the stratosphere than either of the other modes (Fig. 10). Examination of the wave field at the base of the damping layer does not show a signal from this mode, nor was there evidence of significant wave amplitude in mode 3 at other elevations. We therefore focus on untangling the contributions from modes 1 and 2 .

A moderately zoomed in plot of the vertical velocity field from the idealized simulation at $z=10.3 \mathrm{~km}$, the height of the nodal line for mode 1, is shown in Fig. 12a. Figure $12 \mathrm{~b}$ shows the same information at the $11.3-\mathrm{km}$ level, which is the elevation of a nodal line for mode 2 . Consistent with Fig. 7 and with the vertical structure of the trapped modes (Fig. 10), the velocities are weak at both levels, but it is still possible to isolate the signal in each mode. Wave trains are visible in Figs. 12a and 12b, emanating from the topography at several different angles. The dashed black line in both of these panels marks a wave train that appears to originate from southern tip of a side ridge. Similar wave trains appear
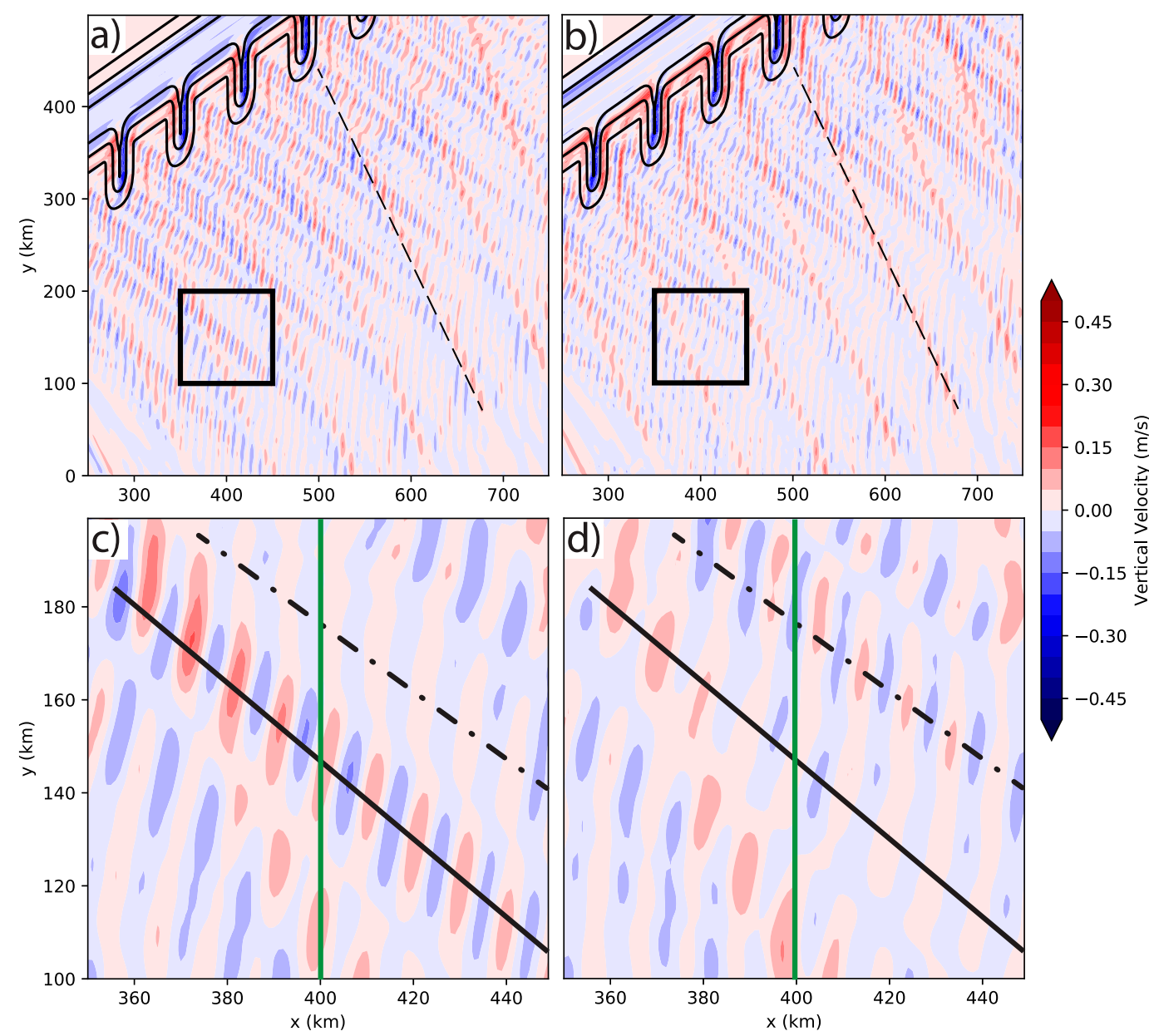

FIG. 12. Vertical velocities (color fill; $\mathrm{m} \mathrm{s}^{-1}$ ) at hour 10 over zoomed-in subdomains of the idealized simulation at heights of (a),(c) 10.3 and (b),(d) $11.3 \mathrm{~km}$. Thin black lines show terrain contours at 1,100, and $300 \mathrm{~m}$. In (a) and (b), the dashed black line shows a reference ray path and the black boxes show the locations of the highly zoomed-in subdomains shown in (c) and (d). Heavy black lines in (c) and (d) illustrate mode-2 ray paths. Dash-dotted black lines in (c) and (d) indicate mode-1 ray paths. The green line segments in (c) and (d) indicate the location of the cross section in Fig. 13. 


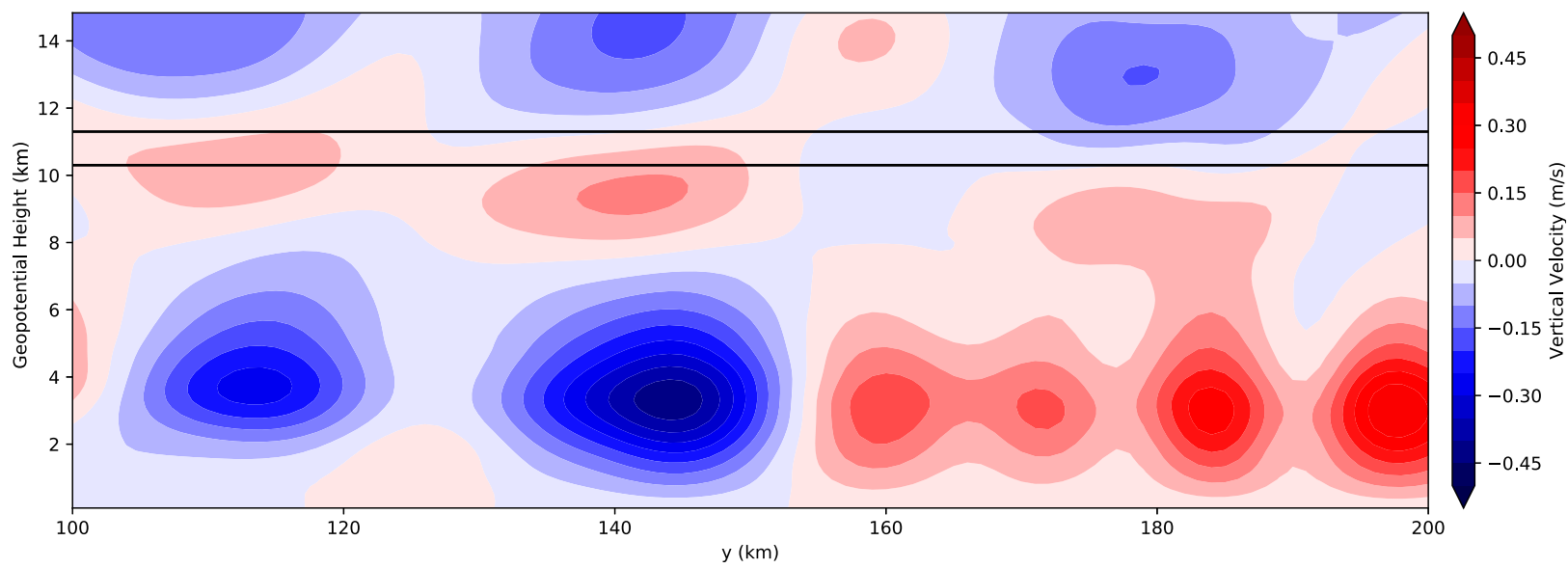

FIG. 13. Contours of $w\left(\mathrm{~m} \mathrm{~s}^{-1}\right)$ in a $y-z$ cross section above $100<y<200 \mathrm{~km}$ at $x=400 \mathrm{~km}$ indicated by the green line in Figs. $12 \mathrm{c}$ and 12d. The lower horizontal black line marks the 10.3-km height of the plots in Figs. 12a and 12c, while the upper line marks the height of the plots Figs. 12b and 12d.

from the tip of the other side ridges; their rapid southward propagation and their origin at the end of the ridge suggests they are "ship-wave-like" features. They do not correspond to any of the output modes of the 2D eigenvalue solver.

Wave packets propagate along ray paths following the group velocity vector, which in the case of the resonant modes with north-south phase lines is $\left(c_{g_{x}}, \bar{V}\right)$, where $V$ is the meridional component of the background wind field, and $\bar{V}$ is some function of $V$ responsible for the north-south translation of the packet. As evident in Fig. $6 \mathrm{~b}, V$ is nearly zero above $10 \mathrm{~km}$, so $\bar{V}$ should be taken as some average over a region of the troposphere. A north-south vertical cross section of $w$ along one of these wave crests (Fig. 13) shows vertically aligned perturbations, indicating that the modes are not being sheared apart by the vertical variations in $V(z)$ and that the maximum amplitude perturbations in the troposphere are largely contained in the layer $1 \leq z \leq 7 \mathrm{~km}$. We therefore estimate $\bar{V}$ as the vertical average of $V$ over this layer $(1-7 \mathrm{~km})$, yielding $\bar{V}=-10.4 \mathrm{~m} \mathrm{~s}^{-1}$.

A comparison of the predicted ray paths with the $w$ perturbations from the idealized simulation is provided on the highly zoomed-in plots in Figs. $12 \mathrm{c}$ and $12 \mathrm{~d}$. The angle of the ray path, with respect to due east, along which a given wave mode propagates is

$$
\theta=\arctan \left(\frac{\bar{V}}{c_{g_{x}}}\right),
$$

which gives ray path angles for mode 1 and mode 2 of $-36^{\circ}$ and $-40^{\circ}$, respectively. Ray paths drawn at these angles are indicated by the dash-dotted and solid black lines, respectively.
At the $10.3-\mathrm{km}$ level, where the mode- 1 perturbations have zero amplitude, Fig. 12c shows a train of waves following the $-40^{\circ}$ line-consistent with this being a group of mode- 2 waves. The wavelength in this group is $10.8 \mathrm{~km}$, which is slightly longer than the $9.5-\mathrm{km}$ value predicted for mode- 2 waves by the linear solver. The $y-z$ vertical cross section in Fig. 13 runs parallel to the phase lines and shows a pair of mode-2-type waves in left half of the plot $(100 \leq x \leq 150 \mathrm{~km})$. The vertical profile of $w$ above $x=145 \mathrm{~km}$ provides a good qualitative match to the mode-2 profile shown in Fig. 10c.

Mode- 2 perturbations are zero at $z=11.3 \mathrm{~km}$, where a train of waves is visible following the more northern $-36^{\circ}$ line - consistent with this being a group of mode- 1 waves. In this case, the simulated wavelengths are $10.5 \mathrm{~km}$, which is slightly longer than the $9.3-\mathrm{km}$ wavelength obtained by the solver. These mode- 1 waves appear in the right half of Fig. 13, and again provide a good qualitative match with the mode-1 vertical profile (Fig. 10b). Note in particular the relative minimum in wave amplitude, without a nodal line, at about $z=6.5 \mathrm{~km}$ in both figures.

\section{Conclusions}

We have shown a large-scale atmospheric environment representative of that upstream of the South Island of New Zealand on 28 July 2014 is capable of supporting a type of trapped lee wave that has never been previously captured in numerical simulations or in observations. The many previous theoretical treatments and numerical simulations of trapped lee waves supported by realistic atmospheric profiles yield modes with maximum velocity perturbations in the lower troposphere and 
exponentially small disturbances in the stratosphere. In contrast, these new lee-wave modes have stratospheric velocity perturbations equal to, or exceeding, those in the troposphere. The key factor supporting the unusual vertical profiles in these waves is the extremely strong and continual increase in the westerly wind speed with height through an altitude of at least $30 \mathrm{~km}$.

These unusual trapped lee waves appear in a full casestudy simulation of the airflow over the Southern Alps, and remain quasi steady for more than half a day. Very similar waves were obtained in an idealized simulation with lower and simpler-shaped topography, and steady horizontally uniform large-scale forcing, that was designed to more clearly isolate the linear wave response. Finally, an eigenvalue-eigenfunction solver was used to determine linear trapped-wave modes supported by both the crossmountain (northwesterly) and the westerly wind profiles for the horizontally uniform environment used in the idealized simulations.

For the westerly flow, in which the winds increase to speeds exceeding $40 \mathrm{~m} \mathrm{~s}^{-1}$ above a height of $23 \mathrm{~km}$, the eigenvalue-eigenfunction solver found three completely trapped modes. They were all higher-order modes having one, two, or three nodal lines and significant amplitude in the stratosphere. Strong evidence was found for the presence of modes 1 and 2 in the idealized simulation. These modes, with phase lines running north-south, were forced by the flow over north-south-oriented side ridges. Because of the nodal structure in the westerly flow modes, the vertical velocities in the layer between 10 and $11 \mathrm{~km}$ were weak in the idealized simulation. They were also weak in the same layer in the full July 28 case-study simulation. Higher up in the stratosphere, the $w$ values in the idealized simulation from modes 1 and 2 intensify dramatically, dominating the wave pattern. In the casestudy simulation, with much more complex topography, modes with north-south-oriented crests become prominent higher in the stratosphere, but do not completely dominate. Despite the evolution of the large-scale environment on 28 July 2014, the simulated wave pattern remained relatively steady for $13 \mathrm{~h}$, suggesting that it may be possible to capture evidence of such trapped waves with appropriately designed observations.

In contrast to the westerly-wind case, the mode supported by the cross-mountain flow was a typical slightly leaky lee wave with maximum amplitude near the $3-\mathrm{km}$ level. Similar lee waves, with maximum amplitude in the lower troposphere and crests parallel to the main spine of the Southern Alps, were present in both the idealized and case-study simulations.

Acknowledgments. This research was funded by National Science Foundation Grant AGS-1545927.
Author Blossey was supported by National Science Foundation Grant AGS-1138977. Author Metz was also supported by an American Meteorological Society Graduate Fellowship. Computational resources were supported in part by a grant of HPC time from the Department of Defense Major Shared Resource Centers, Stennis Space Center, Mississippi.

\section{REFERENCES}

Bacmeister, J. T., and M. R. Schoeberl, 1989: Breakdown of vertically propagating two-dimensional gravity waves forced by orography. J. Atmos. Sci., 46, 2109-2134, https://doi.org/ 10.1175/1520-0469(1989)046<2109:BOVPTD>2.0.CO;2.

Corby, G. A., and C. E. Wallington, 1956: Airflow over mountains: The lee-wave amplitude. Quart. J. Roy. Meteor. Soc., 82, 266274, https://doi.org/10.1002/qj.49708235303.

—_, and J. S. Sawyer, 1958: The air flow over a ridge-The effects of the upper boundary and high-level conditions. Quart. J. Roy. Meteor. Soc., 84, 25-37, https://doi.org/10.1002/ qj. 49708435904.

Danielsen, E. F., and R. Bleck, 1970: Tropospheric and stratospheric ducting of stationary mountain lee waves. J. Atmos. Sci., 27, 758-772, https://doi.org/10.1175/1520-0469(1970) $027<0758$ :TASDOS $>2.0 . \mathrm{CO} ; 2$.

Durran, D. R., 2010: Numerical Methods for Fluid Dynamics with Applications to Geophysics. 2nd ed. Texts in Applied Mathematics, Vol. 32, Springer, 516 pp.

__, 2015: Lee waves and mountain waves. Encyclopedia of Atmospheric Sciences, 2nd ed. G. R. North, Ed., Elsevier, 95-102.

— , and J. B. Klemp, 1983: A compressible model for the simulation of moist mountain waves. Mon. Wea. Rev., 111, 2341-2361, https://doi.org/10.1175/1520-0493(1983)111<2341:ACMFTS> 2.0.CO;2.

— M. O. G. Hills, and P. N. Blossey, 2015: The dissipation of trapped lee waves. Part I: Leakage of inviscid waves into the stratosphere. J. Atmos. Sci., 72, 1569-1584, https://doi.org/ 10.1175/JAS-D-14-0238.1.

Fritts, D. C., and Coauthors, 2016: The Deep Propagating Gravity Wave Experiment (DEEPWAVE): An airborne and groundbased exploration of gravity wave propagation and effects from their sources throughout the lower and middle atmosphere. Bull. Amer. Meteor. Soc., 97, 425-453, https://doi.org/ 10.1175/BAMS-D-14-00269.1.

__ , and Coauthors, 2018: Large-amplitude mountain waves in the mesosphere accompanying weak cross-mountain flow during DEEPWAVE research flight RF22. J. Geophys. Res. Atmos., 123, 9992-10 022, https://doi.org/10.1029/ 2017JD028250.

Gill, A. E., 1982: Atmosphere-Ocean Dynamics, Academic Press, $662 \mathrm{pp}$.

Gisinger, S., and Coauthors, 2017: Atmospheric conditions during the Deep Propagating Gravity Wave Experiment (DEEPWAVE). Mon. Wea. Rev., 145, 4249-4275, https://doi.org/10.1175/ MWR-D-16-0435.1.

Kaifler, B., N. Kaifler, B. Ehard, A. Dörnbrack, M. Rapp, and D. C. Fritts, 2015: Influences of source conditions on mountain wave penetration into the stratosphere and mesosphere. Geophys. Res. Lett., 42, 9488-9494, https://doi.org/10.1002/ 2015 GL066465. 
Kruse, C. G., R. B. Smith, and S. D. Eckermann, 2016: The midlatitude lower-stratospheric mountain wave "valve layer." J. Atmos. Sci., 73, 5081-5100, https://doi.org/10.1175/ JAS-D-16-0173.1.

Scorer, R., 1949: Theory of waves in the lee of mountains. Quart. J. Roy. Meteor. Soc., 75, 41-56, https://doi.org/10.1002/ qj. 49707532308 .

Skamarock, W. C., and Coauthors, 2008: A description of the Advanced Research WRF version 3. NCAR Tech. Note
NCAR/TN-475+STR, 113 pp., https://doi.org/10.5065/ D68S4MVH.

Smith, R. B., and Coauthors, 2016: Stratospheric gravity wave fluxes and scales during DEEPWAVE. J. Atmos. Sci., 73, 2851-2869, https://doi.org/10.1175/JAS-D-15-0324.1.

Vadas, S. L., D. C. Fritts, and M. J. Alexander, 2003: Mechanism for the generation of secondary waves in wave breaking regions. J. Atmos. Sci., 60, 194-214, https://doi.org/10.1175/ 1520-0469(2003)060<0194:MFTGOS >2.0.CO;2. 